\title{
Refining the surgical playbook for treating colorectal cancer liver metastases
}

\author{
Luis I. Ruffolo^, Roberto Hernandez-Alejandro, Koji Tomiyama \\ Division of Transplantation and Hepatobiliary Surgery, Department of Surgery, University of Rochester Medical Center, Rochester, NY, USA \\ Correspondence to: Luis I. Ruffolo, MD. Division of Transplantation and Hepatobiliary Surgery, Department of Surgery, University of Rochester \\ Medical Center, Rochester, NY, USA. Email: luis_ruffolo@urmc.rochester.edu. \\ Comment on: Mor E, Al-Kurd A, Yaacov AB, et al. Surgical outcomes of two-stage hepatectomy for colorectal liver metastasis: comparison to a \\ benchmark procedure. Hepatobiliary Surg Nutr 2019;8:29-36.
}

Submitted Jan 31, 2021. Accepted for publication Feb 25, 2021.

doi: 10.21037/hbsn-21-31

View this article at: http://dx.doi.org/10.21037/hbsn-21-31

Adenocarcinoma of the colon and rectum (CRC) is the second leading cause of cancer-related mortality. Surgical resection of disease offers the best long-term survival. Unfortunately, $>50 \%$ of patients have liver metastases at the time of diagnosis, or develop colorectal cancer liver metastases (CRLM) subsequent to treatment of primary disease. Metastasectomy of CRLM has proven to extend survival, with up to $50 \% 5$-year overall survival in contemporary series. However, only the minority of patients present with resectable disease; technical resectability is the ability to remove all carcinoma with negative microscopic margins while leaving adequate future liver remnant (FLR). FLR volume serves as a surrogate for functional reserve, and a FLR of $\geq 30 \%$ in chemotherapy-treated patients is considered the minimum necessary volume to prevent complications of liver failure. In cases where predicted FLR is inadequate, vascular modulatory techniques such as portal vein embolization (PE) alone or in combination with two-stage hepatectomy (TSH-PE) or associating liver partition-and portal vein ligation for staged hepatectomy (ALPPS) have been shown to augment small FLR and provide an opportunity for curative resection. However the more radical the resection the higher the chance of a major complication after surgery (1). Thus, it is imperative to consider both the technical resectability of liver lesions along with the underlying tumor biology in order to weigh the benefit of radical resection for CRLM. Here we discuss recent findings from Mor et al. in perioperative outcomes after TSH-PE and discuss the current landscape of surgical approaches available for combating liver metastases from colorectal cancer.

Mor et al. present their experience from a single institutions retrospective review of ten years of patients who underwent TSH-PE for CRLM, and compared the observed perioperative complications with a cohort of patients who underwent right hepatectomy for CRLM (2). In these cohorts of patients, the observed major complication rate and overall-survival was similar between TSH-PE and RH cohorts $(17.2 \%$ and $20 \%$ major complication rate, $3.7 \%$ and $0 \%$ perioperative mortality respectively). Notably the authors reported a high utilization rate of ablative strategies to spare liver volume $(79.2 \%$ of patients completing the second stage). This is noteworthy given the available data which suggests that ablative approaches have a four-fold risk of recurrence compared to resection (3). Nonetheless, this report adds further evidence to the feasibility of major hepatic resection and vascular modulatory techniques for aggressive treatment of colorectal liver metastases.

Approaching bilobar CRLM with TSH-PE is now routinely utilized, with reported perioperative morbidity and mortalities which eclipse major hepatic resections. Beyond TSH-PE, ALPPS has more recently become adopted for insufficient FLR, and a body of evidence has accumulated demonstrating it offers superior resectability and improved overall survival when compared head to head with TSH-PE in a multi-centered randomized-

\footnotetext{
^ ORCID: 0000-0001-6002-9559.
} 
controlled trial (4). Respectively, both approaches should be viewed as tools which can extend the option for patients with disseminated liver metastases. However, technical resectability does not belie favorable biology.

Surgical treatment of metastatic disease at its core is a calculated gamble, one where the approach should have a reasonable chance of long-term disease control based on the natural history of the underlying malignancy. As we know, not all colorectal cancers behave the same. Disease aggressiveness can be predicted in part based on site of origin, response to chemotherapy, nodal involvement, and the time from the development of the primary tumor to the discovery of liver metastases (5). Furthermore, molecular analyses of driver oncogenes have shown the intracellular machinery which drives recurrence, metastases, and treatment failure. The more we learn about anatomic, temporal, and molecular markers of aggressiveness, the more we are able to gauge disease biology. Thus, as patients present to our clinics with CRLM of various lobar distributions but also tumor phenotypes, we must incorporate both assessments of technical and oncological resectability.

Perhaps the prime example of this concept is now being employed around the world in centers performing liver transplantation (LT) for CRLM. Work from prospective trials have shown five year overall-survival which approach $80 \%$ in highly selected patients who are offered LT as a means of local tumor control (6). To date, eight trials have been registered to study the efficacy of LT for CRLM, and many other centers have begun to offer LT for CRLM within institutional treatment protocols. Central to the rationale of this approach is the implementation of selection criteria which identify patients who have favorable tumor biology. Thus, centers require a minimum period of tumor response to chemotherapy, and some exclude patients based on driver oncogene status. In addition, patients must have no evidence of extrahepatic disease, and must have had their primary tumor addressed prior to consideration.

One interesting finding from the early experience of implementing LT for CRLM is a surprisingly skewed distribution of recurrent disease. For example, patients who undergo major hepatectomy for CRLM experience hepatic recurrence about $40 \%$ of the time in the remnant liver. However, patients who undergo LT experience far lower rates of liver recurrence (3\%) (7). This may be due to the preselection of patients prior to LT, but an alternative explanation may be the effects of total hepatectomy and removal of micrometastases. As more experience accumulates with this approach, there may come a day when we consider LT for patients with borderline resectable tumors and favorable oncologic characteristics, if indeed total hepatectomy can improve long term-disease control in highly selected patients. However for now data must accumulate to understand the derived benefit of LT for CRLM, and further refine a consensus criteria for offering this option to patients.

In summary, recent advances in vascular modulatory techniques including TSH-PE and ALPPS have expanded the armamentarium for treating CRLM with acceptable perioperative morbidity and good overall survival. Total hepatectomy and LT appears to be both feasible and beneficial in the right patient population. However, we must continue to build knowledge and stratification criteria for selecting the right surgical approach when treating patients with metastatic colon cancer through multi-institutional trials. To this effect, we present our institution's approach when assessing the biology and anatomy of patients' CRLM (Figure 1). 


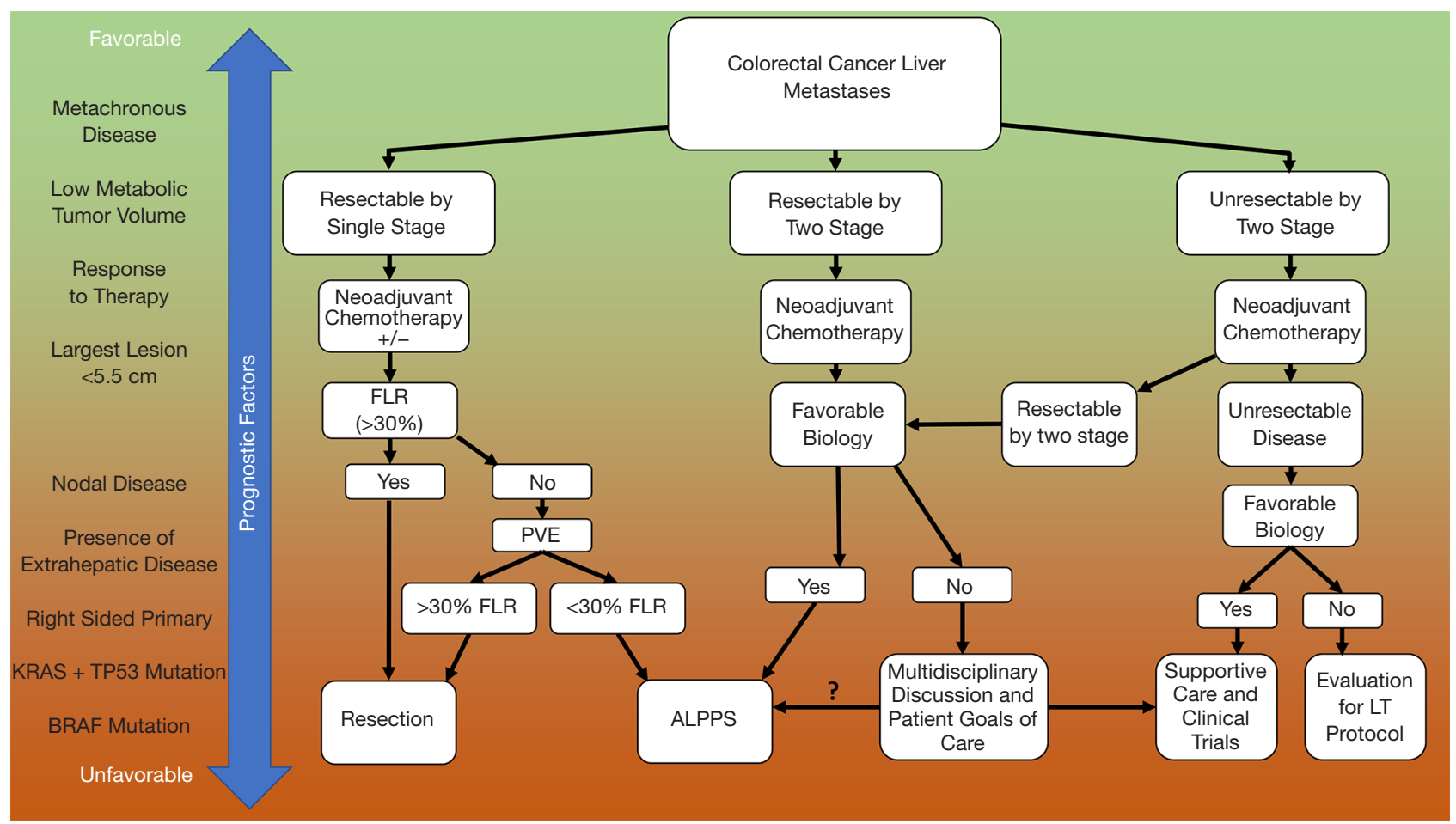

Figure 1 Decision diagram for evaluating patients with colorectal liver metastasis who present without evidence of extrahepatic disease. Tumor characteristics are critical to evaluating favorable and unfavorable biology, and are demonstrated on a spectrum to the left.

\section{Acknowledgments}

Funding: None.

\section{Footnote}

Provenance and Peer Review: This article was commissioned by the editorial office of Hepatobiliary Surgery and Nutrition. The article did not undergo external peer review.

Conflicts of Interest: All authors have completed the ICMJE uniform disclosure form (available at https://hbsn. amegroups.com/article/view/10.21037/hbsn-21-31/coif). The authors have no conflicts of interest to declare.

Ethical Statement: The authors are accountable for all aspects of the work in ensuring that questions related to the accuracy or integrity of any part of the work are appropriately investigated and resolved.

Open Access Statement: This is an Open Access article distributed in accordance with the Creative Commons Attribution-NonCommercial-NoDerivs 4.0 International
License (CC BY-NC-ND 4.0), which permits the noncommercial replication and distribution of the article with the strict proviso that no changes or edits are made and the original work is properly cited (including links to both the formal publication through the relevant DOI and the license). See: https://creativecommons.org/licenses/by-nc-nd/4.0/.

\section{References}

1. Hernandez-Alejandro R, Bertens KA, Pineda-Solis $\mathrm{K}$, et al. Can we improve the morbidity and mortality associated with the associating liver partition with portal vein ligation for staged hepatectomy (ALPPS) procedure in the management of colorectal liver metastases? Surgery 2015;157:194-201.

2. Mor E, Al-Kurd A, Yaacov AB, et al. Surgical outcomes of two-stage hepatectomy for colorectal liver metastasis: comparison to a benchmark procedure. Hepatobiliary Surg Nutr 2019;8:29-36.

3. Abdalla EK, Vauthey JN, Ellis LM, et al. Recurrence and outcomes following hepatic resection, radiofrequency ablation, and combined resection/ 
ablation for colorectal liver metastases. Ann Surg 2004;239:818-25; discussion 825-7.

4. Hasselgren K, Røsok BI, Larsen PN, et al. ALPPS Improves Survival Compared With TSH in Patients Affected of CRLM: Survival Analysis From the Randomized Controlled Trial LIGRO. Ann Surg 2021;273:442-8.

5. Dueland S, Grut H, Syversveen T, et al. Selection criteria related to long-term survival following liver

Cite this article as: Ruffolo LI, Hernandez-Alejandro R, Tomiyama K. Refining the surgical playbook for treating colorectal cancer liver metastases. HepatoBiliary Surg Nutr 2021;10(3):397-400. doi: 10.21037/hbsn-21-31 transplantation for colorectal liver metastasis. Am J Transplant 2020;20:530-7.

6. Line PD, Ruffolo LI, Toso C, et al. Liver transplantation for colorectal liver metastases: What do we need to know? Int J Surg 2020;82S:87-92.

7. Hagness M, Foss A, Egge TS, et al. Patterns of recurrence after liver transplantation for nonresectable liver metastases from colorectal cancer. Ann Surg Oncol 2014;21:1323-9. 